CLINICAL STUDY

\title{
CDKN1B V109G polymorphism a new prognostic factor in sporadic medullary thyroid carcinoma
}

\author{
Daniela Pasquali*, Luisa Circelli ${ }^{1,2, *}$, Antongiulio Faggiano ${ }^{3}$, Massimo Pancione ${ }^{1}$, Andrea Renzullo, Rossella Elisei ${ }^{4}$, \\ Cristina Romei ${ }^{4}$, Giacomo Accardo, Viviana Raffaella Coppola, Maurizio De Palma ${ }^{5}$, Piero Ferolla ${ }^{6}$, \\ Franco Grimaldi $^{7}$, Annamaria Colao ${ }^{8}$ and Vittorio Colantuoni ${ }^{1}$ \\ Dipartimento Medico-Chirurgico di Internistica Clinica e Sperimentale 'F. Magrassi e A. Lanzara', Seconda Università di Napoli, 80131 Napoli, Italy, \\ ${ }^{1}$ Dipartimento di Scienze Biologiche ed Ambientali, Università degli Studi del Sannio, Via Port'Arsa, 82100 Benevento, Italy, ${ }^{2} e$ CEINGE SCARL, \\ Biotecnologie Avanzate, 80131 Napoli, Italy, ${ }^{3}$ IRCCS Fondazione SDN, 80121 Napoli, Italy, ${ }^{4}$ Dipartimento di Endocrinologia e Metabolismo, Università \\ di Pisa, 56124 Pisa, Italy, ${ }^{5}$ A. O. 'A. Cardarelli', VI Chirurgia, 80131 Napoli, Italy, ${ }^{6}$ Dipartimento di Medicina Interna e Endocrinologia, Università di \\ Perugia, 06100 Perugia, Italy, ${ }^{7}$ Unità di Endocrinologia, 'S. Maria della Misericordia' Ospedale di Udine, 33100 Udine, Italy and ${ }^{8}$ Dipartimento di \\ Endocrinologia ed Oncologia Molecolare e Clinica, Facoltà di Medicina e Chirurgia, Università 'Federico II', 80131 Napoli, Italy
}

(Correspondence should be addressed to V Colantuoni; Email: colantuoni@unisannio.it)

*(D Pasquali and L Circelli contributed equally to this work)

\begin{abstract}
Context: CDKN1B encodes the cyclin-dependent kinase inhibitor p27Kip1 and is mutated in multiple endocrine neoplasia-like syndromes. CDKN1B also harbors single nucleotide polymorphisms; the T/G transversion at nucleotide 326 (the V109G variant) has been reported to be protective in breast, hereditary prostate, and pancreatic tumors. Association of CDNK1B mutations or polymorphisms with sporadic medullary thyroid carcinoma (MTC) has not been investigated yet.

Objective and design: We screened germline DNA from 84 patients affected by sporadic MTC and 90 healthy age- and gender-matched controls for CDKN1B mutations or polymorphisms by PCR amplification and sequencing of the amplicons. We also tested all germline and 50 tumor tissue DNA for RET proto-oncogene mutations. Computed tomography, ultrasound scans, and serum calcitonin were carried out before surgery and during the follow-up and associated with CDKN1B polymorphism and disease remission.

Results: The T/G transversion at nucleotide 326 was the only DNA variation detected. The overall frequency of the $\mathrm{T} / \mathrm{G}$ and $\mathrm{G} / \mathrm{G}$ alleles in combination was $46.4 \%$. This variant (V109G) was correlated with post-operative calcitonin levels in the normal range and biochemical remission. Conversely, the wild-type (T/T) allele was associated with post-operative calcitonin levels above normal and a higher risk to develop clinical recurrence and distant metastases. Somatic RET mutations were significantly associated with a more aggressive behavior especially in wild-type allele-bearing patients.

Conclusions: Collectively, in sporadic MTC, the CDKN1B V109G polymorphism correlates with a more favorable disease progression than the wild-type allele and might be considered a new promising prognostic marker.
\end{abstract}

European Journal of Endocrinology 164 397-404

\section{Introduction}

CDKN1B encodes the cyclin-dependent kinase (Cdk) inhibitor $\mathrm{p} 27 \mathrm{Kip} 1$, a regulatory protein that controls the progression from the $\mathrm{G} 1$ to the $\mathrm{S}$ phase of the cell cycle by interacting with cyclinE/Cdk2 and cyclinD1/Cdk4 complexes $(1,2)$. Loss-of-function mutations have been described and contribute to tumorigenesis. Specifically, mutations of the p27Kip1 $(C d k n 1 b)$ gene in rat are associated with the development of a MEN X syndrome characterized by a clinical picture that overlaps MEN 1 and MEN 2 syndromes ((3) and references therein). In humans, a MEN 1-like syndrome has recently been described and referred as MEN $4(3,4)$. No mutations in CDKN1B have been found in 16 patients with a MEN 1 phenotype without MEN 1 mutations $(5,6)$, suggesting that $C D K N 1 B$ germline mutations can predispose to the development of endocrine tumors in humans $(3,4,7)$. A total of 21 single nucleotide polymorphisms in CDKN1B have also been described, 11 of which have low allelic frequency (5\%) and 9 occur within the non-coding regions of the gene $(8,9)$. A single nucleotide polymorphism $(\mathrm{T} / \mathrm{G})$ at position 326 that causes a glycine for valine amino acid substitution at codon 109 of the mature protein has variably been associated with cancer risk and progression in several tumors including 
prostate $(10,11)$, breast $(12,13)$, oral squamous cell (14), and pancreatic carcinomas $(15,16)$. The frequency of the variant in such tumors ranges from 6 to $40 \%$ and appears not to be significantly different from controls (10-16). So far, no evidence has been provided to support the association of CDKN1B mutations or polymorphisms with tumor progression and outcome in medullary thyroid carcinoma (MTC). This tumor arises from the neural crest-derived calcitonin-producing or parafollicular $\mathrm{C}$ cells of the thyroid gland $(17,18)$ and occurs sporadically in about $75 \%$ of cases or as a component of the autosomal dominantinherited MEN 2 syndromes or as a unique manifestation of the familial MTC (FMTC) (19-22). Mutations of the RET proto-oncogene are responsible for the large majority of MEN 2 and FMTC cases $(23,24)$ and for a proportion of sporadic MTCs. It is still unknown whether another frequently mutated gene or multiple low frequency mutated genes are responsible for MTCs not bearing RET mutations. Moreover, the clinical phenotype of sporadic and inherited MTCs is heterogeneous even in the presence of the same mutation; also the relationship with the clinical course and prognosis may be variable and the molecular mechanisms are still under investigation. The search of new biomarkers that can easily and objectively be determined can help in MTC diagnosis and management. Since the V109G polymorphism has been associated with endocrine tumors, in this study, we sought to search for CDKN1B mutations or polymorphisms, specifically for the V109G polymorphism, in a large sample of sporadic MTCs negative for germline RET mutations and correlate its presence with disease progression.

\section{Subjects and methods}

\section{Study subjects}

Eighty-four consecutive patients, 34 males and 50 females, diagnosed with sporadic MTC at the participating institutions from 1999 to 2009, were enrolled in this study. They were selected on the basis of a lack of known RET germline mutations, family history of thyroid diseases, negative clinical, laboratory, and family data for any other malignancy or predisposition to develop it. No loss of follow-up or study end-data was observed in our subjects. Cancer-related death occurred in a single patient. Patients' mean age at diagnosis was $46.1 \pm 13.2$ years, and the median follow-up was 84.0 months. All affected individuals were subjected to total thyroidectomy and central neck dissection following standard procedures. Lymphadenectomy of the lateral compartment(s) was performed during the first surgery if node metastases were already diagnosed or detected during the intervention. Ninety subjects, age $( \pm 5$ years) and gender-matched with the enrolled patients, served as control. Thirty-six male and fifty-four female individuals aged $<60$ year old, with no history of MTC, basal serum calcitonin levels $<10 \mathrm{pg} / \mathrm{ml}$, and absence of thyroid nodules, were recruited among the medical and paramedical personnel of the institutions participating in the present study. These criteria were designed to ensure that all of them had a minimal risk of having or ever developing an MTC. After informed consent was obtained, each subject was interviewed using a pretested questionnaire to obtain information on medical history, lifestyles, and family history of cancer up to first-degree relatives. Based on these information, the control group does not include individuals with history of breast, hereditary prostate and pancreatic tumors, or any other cancer. All patients and controls were of European descent with a nationwide distribution. Informed consent for all genetic screenings, blood samples handling and processing, and other clinical procedures was provided by all investigated subjects in accordance with the guidelines approved by the local ethical committee. Serum calcitonin and carcinoembryonic antigen (CEA) were employed as MTC tumor markers; serum calcitonin was measured before and routinely after surgery, recording the trend of the last few determinations, for the long-term surveillance, according to the recommendation of the American Thyroid Association Guidelines Task Force (25).

\section{Serum calcitonin assay}

Serum calcitonin was measured by a commercially available IRMA test (Byk Gulden Italia S.p.A., Milan, Italy) according to the manufacturer's instructions, as previously described (26).

\section{Analysis of the CDKN1B V109G polymorphism and RET mutation}

The analysis was performed on germline DNA from patients and control blood samples. CDKN1B exons 1 and 2 were PCR amplified using the following oligonucleotides as primers: exon1 fw: GTAGGGGGCTTTGTTTTG, rev: GCCAGGTAGCACTGAACACC; exon2 fw: GTAGGGGCGCTTTGTTTG, rev: ACAGGGAAACGACCTTCCTAC; and the following amplification conditions: $5 \mathrm{~m}$ for the initial denaturation step at $95^{\circ} \mathrm{C}$ followed by 35 cycles of $15 \mathrm{~s}$ at $94{ }^{\circ} \mathrm{C}, 30 \mathrm{~s}$ at $60^{\circ} \mathrm{C}, 1 \mathrm{~m}$ at $72^{\circ} \mathrm{C}$, and a final $5 \mathrm{~m}$ step at $72{ }^{\circ} \mathrm{C}$ for the final extension. RET proto-oncogene mutations were searched by PCR amplification of exons 8,10,11,13,14, 15, and 16 on germline DNA from all patients and somatic DNA from 50 tumor samples using the primers reported in the literature $(27,28)$. All PCR products were isolated and subjected to automatic sequence analysis (Applied Biosystem Bioprism 3100, Foster City, CA, USA). The tests were performed on at least three different germline DNA preparations obtained from independent drawings. Also the tumor tissue analysis was carried out on two different DNA preparations. 


\section{Statistical analysis}

All statistical analyses were carried out with the SPSS (version 15.0) for Windows (SPSS, Inc., Chicago, IL, USA). The $\chi^{2}$, Fisher exact, or the Spearman test was employed to assess the association of the V109G polymorphism with several biochemical, clinicopathological parameters and RET mutations. The influence of the p27Kip1 polymorphism and other clinico-pathological variables on disease-free survival (DFS) was evaluated by the Kaplan-Meier method; differences were analyzed with the log-rank test. Cox regression models were used to evaluate the effect of the CDKN1B polymorphism on patients' outcome after adjusting for other covariates or potential confounders. Several clinico-pathological variables were included in the final multiple regression model whereby hazard rate (HR), 95\% confidence interval (95\% CI), and significance levels were estimated. A stepwise selection procedure was used to identify those markers that independently predict disease progression. The analysis of variance between groups was performed by ANOVA. Data were reported as mean \pm s.D., and the mean values were compared using the Student's $t$-test or the MannWhitney $U$ test. Results were considered statistically significant when a $P \leq 0.05$ was obtained.

\section{Results}

\section{CDKN1B polymorphism detection in MTC patients and control subjects}

To determine whether CDKN1B mutations or single nucleotide polymorphisms are associated with MTC disease progression, we genotyped $n=84$ patients affected by sporadic MTC and $n=90$ matched controls. The analysis was carried out on germline DNA by PCRamplifying exons 1 and 2 of the gene, followed by automatic sequencing. The only gene variation was the $\mathrm{T} / \mathrm{G}$ transversion at nucleotide 326 of exon 1 (rs2066827) that causes a valine (GTC) for glycine (GGC) substitution at position 109 of the mature protein (Fig. 1A). Only a slight, borderline difference in the frequency of the wild-type $(\mathrm{T} / \mathrm{T}, 53.6 \%)$ and polymorphic alleles (T/G 45.2\%, G/G 1.2\%) was found between patients and controls $(P=0.048$; Fig. 1B). The search for RET mutations was performed by amplifying exons 8-16 from germline DNA of all patients and from somatic DNA extracted from 50 available tumor tissues and sequencing the obtained amplicons. All patients were negative for RET germline, whereas RET somatic mutations were found in 13/50 tumor tissue DNA $(26 \%)$, a percentage slightly lower than that reported in the literature $(25,26)$. They were equally distributed between wild-type- and polymorphism-bearing patients, 25.9 vs $26.1 \%$ respectively. Twelve cases $(24 \%)$ had the M918T mutation, and a single patient had the C634W mutation (2\%). The RET genetic test data do

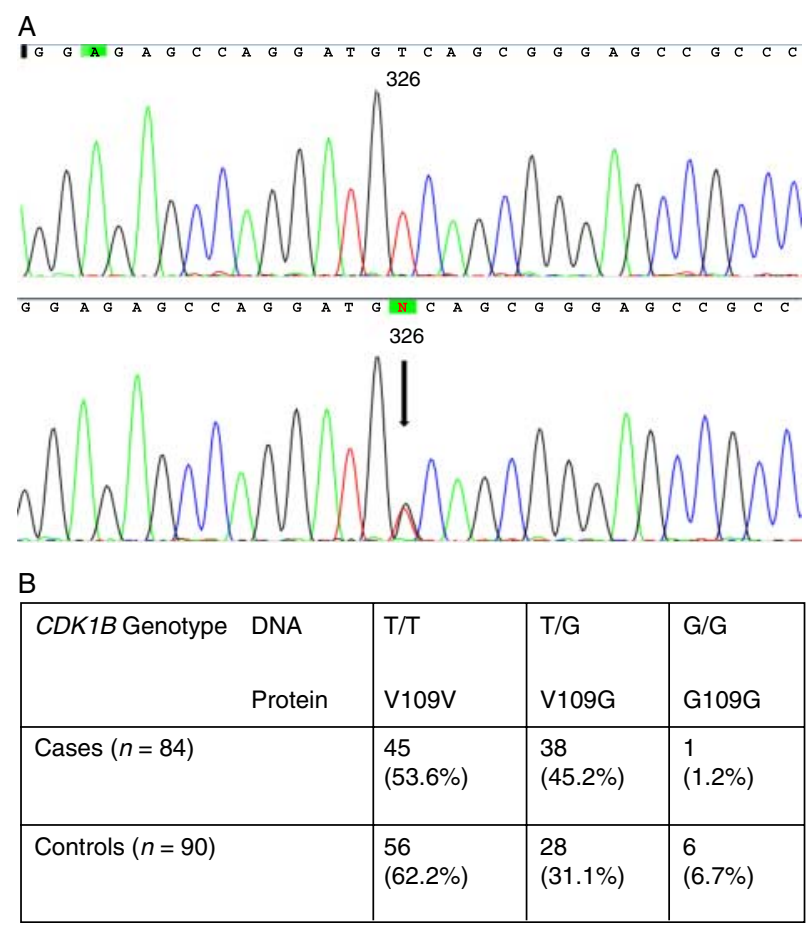

Figure 1 Identification of the CDKN1B V109G single nucleotide polymorphism and its allelic frequency in MTC patients and controls. (A) Direct sequencing of CDKN1B-amplified exon 1 from two patients' DNA shows either the wild-type sequence or the T/G transversion at nucleotide 326 . The arrow in the lower electropherogram denotes two overlapping peaks, indicative of the presence of two different nucleotides at that position of the sequence. The change causes a valine (GTC) for glycine (GGC) substitution at position 109 of the mature protein. (B) Relative frequency of the T/G (V109G) polymorphism in patients and control individuals. Full colour version of this figure available via http://dx.doi.org/10.1530/EJE-10-0929.

not rule out mutations that may be present in the exons not investigated both in the germline and in the somatic DNA.

\section{Clinico-pathological parameters, CDKN1B polymorphism, and serum calcitonin levels}

Patients were subdivided into two groups, WT (T/T genotype) and POL (a combination of T/G and $\mathrm{G} / \mathrm{G}$ genotypes) according to the presence of the CDKN1B wild-type or polymorphic allele respectively. The CDKN1B genetic status and some of the clinicopathological characteristics of the patients analyzed are reported in Table 1. Patients' age, gender, tumor stage, and last post-operative serum calcitonin levels from WT were compared with POL patients (Table 1). The age at diagnosis was lower in POL than in WT patients $(P=0.026)$. An association was found between the CDKN1B genetic status and the T stage, i.e. wild-type allele-bearing patients had a more advanced (T3/T4) tumor than patients with the polymorphic allele 
Table 1 Relationship between CDKN1B polymorphism, clinical and biochemical data of the MTC patients investigated. Patients enrolled in this study were divided into two groups. The WT group carries the $C D K N 1 B T / T$ allele corresponding to the valine at position 109 of the mature protein. The POL group carries both the $T / G$ and $G / G$ alleles corresponding to the amino acid glycine of the mature protein (V109G). CT last, last post-operative calcitonin levels.

\begin{tabular}{|c|c|c|c|c|}
\hline \multirow[b]{2}{*}{ Parameters } & \multicolumn{4}{|c|}{ CDKN1B } \\
\hline & $n$ & WT & POL & $P$ value \\
\hline Mean \pm s.D. age (y) & 84 & $49.3 \pm 13.7$ & $45.0 \pm 13.1$ & 0.901 \\
\hline $\begin{array}{l}\text { Mean } \pm \text { s.D. } \\
\text { follow-up (months) }\end{array}$ & 84 & $85.5 \pm 54.3$ & $94.2 \pm 52.2$ & 0.102 \\
\hline Age (years) & & & & $0.026^{*}$ \\
\hline$\leq 45$ & 39 & 18 & 21 & \\
\hline$>45$ & 45 & 27 & 18 & \\
\hline Gender & & & & 0.109 \\
\hline $\mathrm{F}$ & 50 & 25 & 25 & \\
\hline M & 34 & 20 & 14 & \\
\hline T stage & & & & $0.05^{\star}$ \\
\hline $\mathrm{T} 1$ & 21 & 11 & 10 & \\
\hline T2 & 47 & 23 & 24 & \\
\hline T3 & 6 & 4 & 2 & \\
\hline $\mathrm{T} 4$ & 10 & 7 & 3 & \\
\hline N stage & & & & 0.105 \\
\hline No & 39 & 19 & 20 & \\
\hline N1/N2 & 45 & 26 & 19 & \\
\hline M stage & & & & $0.0001^{\dagger}$ \\
\hline M0 & 75 & 38 & 37 & \\
\hline M1 & 9 & 7 & 2 & \\
\hline Tumor stage & & & & 0.458 \\
\hline I & 21 & 11 & 10 & \\
\hline II & 17 & 8 & 9 & \\
\hline III & 32 & 18 & 14 & \\
\hline IV & 15 & 8 & 6 & \\
\hline CT last ${ }^{a}$ & & & & $0.0001^{\dagger}$ \\
\hline$\leq 10$ & 36 & 13 & 23 & \\
\hline$>10-150$ & 19 & 10 & 9 & \\
\hline$>150$ & 29 & 22 & 7 & \\
\hline Total & 84 & 45 & 39 & \\
\hline
\end{tabular}

*Significant at 0.05 level; ${ }^{\dagger}$ significant at 0.01 level.

${ }^{\mathrm{a}}$ Recommendations 73 and 74 given in Kloos et al. (25).

$(P=0.05)$. Interestingly, a strong correlation was found between the presence of distant metastases and the CDKN1B wild-type allele ( 78 vs $22 \%$, Table 1 , $P=0.0001$ ). The pre-operative serum calcitonin did not show significant differences between the two groups (Fig. 2; $P=0.988$ ). In contrast, the last postoperative serum calcitonin was within the normal range in 13 WT subjects compared to 23 POL patients (29 vs $59 \% ; P=0.0001)$, whereas it was frankly elevated $(>150 \mathrm{pg} / \mathrm{ml})$ in $22 \mathrm{WT}$ cases compared with only 7 POL cases (49 vs $18 \%$; $P=0.0001$ ) (Table 1 and Fig. 2). The calcitonin data suggest a robust inverse relationship between last post-operative serum levels and the presence of the CDKN1B polymorphism. Moreover, only post-operative levels were significantly higher in WT than in POL patients when the median absolute values were considered (234 vs $7.7 \mathrm{pg} / \mathrm{ml}$, Fig. 2). Collectively, these data suggest a more aggressive course of the MTC in patients bearing the CDKN1B wild-type allele as compared with the polymorphism-bearing patients.

\section{Relationship between RET mutations and recurrence rate in MTC patients}

The overall clinical follow-up was available for all patients and determined starting from the day of the first surgery with a median of 84.0 months. All 22 patients bearing the $C D K N 1 B$ wild-type allele had serum calcitonin levels $>150 \mathrm{pg} / \mathrm{ml}$ and experienced clinical recurrences with symptomatic progressive loco-regional disease. Thirteen wild-type allele-bearing patients, with serum calcitonin levels in the normal range, were in biochemical remission with no signs of persistent or recurrent disease. On the other hand, 23 patients bearing the polymorphism had serum calcitonin levels in the normal range and were in biochemical remission as evidenced by lack of signs or symptoms, imaging data, and long-term follow-up. In contrast, only seven polymorphism-bearing patients had serum calcitonin levels above $150 \mathrm{pg} / \mathrm{ml}$ and presented clinical recurrences. Patients with calcitonin values ranging from 10 to $\max 150 \mathrm{pg} / \mathrm{ml}$ were considered in biochemical recurrence and were equally distributed between the POL and WT groups (Table 1). For statistical purpose, we stratified the patients into two groups: the first group included patients with biochemical remission (with calcitonin levels in the normal range $\leq 10 \mathrm{pg} / \mathrm{ml}$ ); the second group included patients with biochemical/clinical recurrence and calcitonin levels above normal range $(>10 \mathrm{pg} / \mathrm{ml}$ ). Kaplan-Meier analysis performed on the two groups showed a significant association of polymorphism-bearing patients with a longer DFS (Fig. 3). Somatic RET mutations (13/50 cases analyzed) were equally distributed between the WT and POL groups

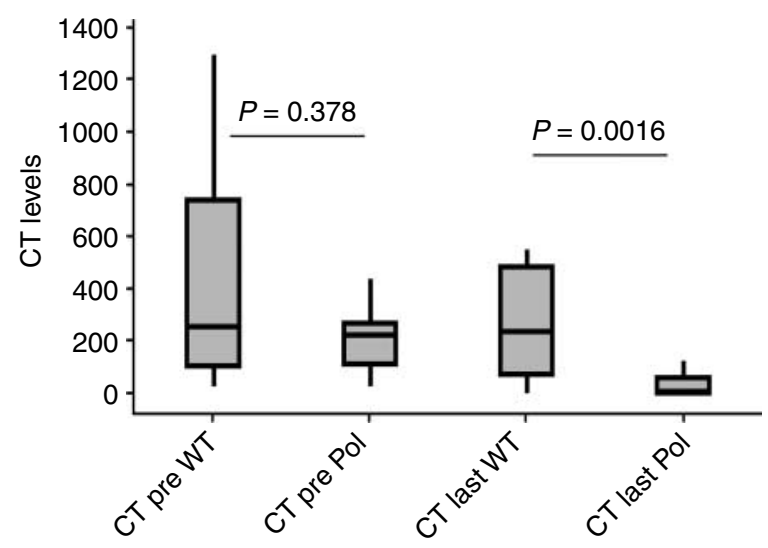

Figure 2 Serum calcitonin levels in patients carrying the $C D K N 1 B$ wild-type or polymorphic allele. The pre- and last post-operative calcitonin levels are represented by box plot for each group of patients, carrying either the CDKN1B wild-type (T/T genotype) or the polymorphic allele (a combination of $T / G$ and $G / G$ genotypes) respectively. The edges of the boxes are the interquartile range box, and lines in the box represent the median value. CT levels, calcitonin levels; CT pre WT, pre-operative calcitonin levels in wild-type group; CT pre POL, pre-operative calcitonin levels in polymorphic group; CT last, last post-operative calcitonin levels in both groups. 


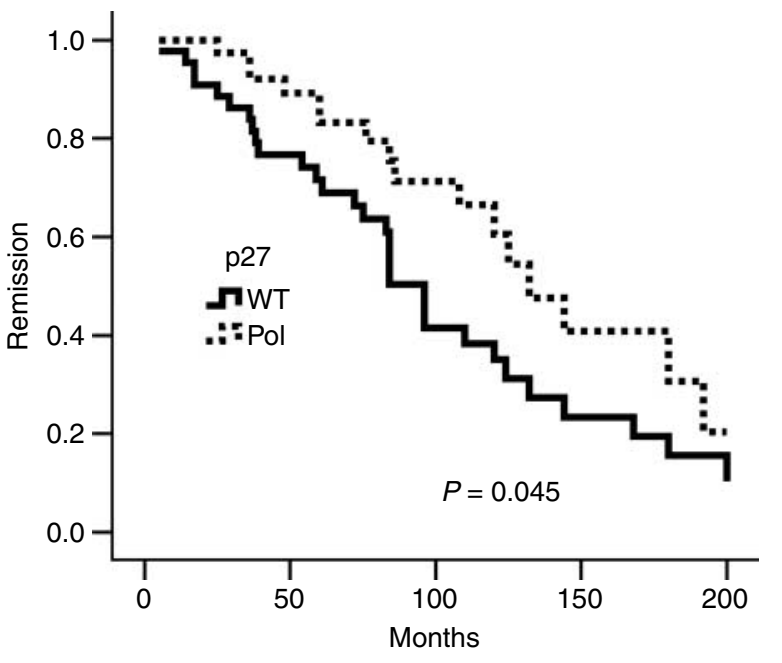

Figure 3 Relationship of the CDKN1B genetic profile with MTC remission. Kaplan-Meier analysis was referred to the CDKN1B genetic status. The $P$ value reported in the graph was obtained with the log-rank test. Wild-type group refers to $T / T$ genotype; polymorphic group comprises a combination of $\mathrm{T} / \mathrm{G}$ and $\mathrm{G} / \mathrm{G}$ alleles. WT, CDKN1B wild type; POL, CDKN1B V109G polymorphism.

(Table 2) and were associated with a more aggressive course of the disease especially in CDKN1B WT allelebearing patients, as documented by the presence of distant metastases, advanced $\mathrm{T}$ stage (T3/T4), and higher calcitonin levels (Table 2). No relationship was found for other clinico-pathological variables such as gender, lymph node involvement, and patients' age at diagnosis (data not shown).

\section{Univariate and multivariate analysis}

To assess whether the CDKN1B V109G polymorphism and the clinico-pathological variables have a prognostic significance, Cox regression analysis was performed for
83 patients, because only one cancer-related death occurred in our series (Table 3). Univariate analysis showed that the CDKN1B polymorphism significantly correlates (HR calculation with a 95\% CI) with DFS when patients were stratified as in biochemical remission or in biochemical/clinical recurrence with calcitonin levels above normal range. This indicates that patients carrying the CDKN1B wild-type allele have a relative higher risk of recurrence than patients carrying the polymorphism. Multivariate model showed that CDKN1B genetic status preserves a prognostic significance when adjusted for tumor stage $(P<0.05$; Table 3). No significant effects were observed when other variables such as age at diagnosis or gender were included in the multivariate model. In a similar analysis, performed taking into account only the subgroup of $n=50$ patients analyzed for somatic RET mutations, the polymorphism significantly correlated with patients' outcome when adjusted for RET mutations ( $P$ interaction $<0.05$, Table 3$)$. These data suggest that the CDKN1B polymorphism could be a potential prognostic factor for disease progression in MTC patients.

\section{Discussion}

Over the past years, great attention has been paid to the new achievements in understanding several aspects of MEN 2 syndromes, including the identification of new clinical entities and genes. A MEN 1-like syndrome, defined MEN X, has been described in rats with a clinical picture that partially overlaps MEN 1 and MEN 2A phenotypes (3). Pellegata et al. identified a nonsense mutation in the CDKN1B human gene as a causative alteration that results in a dramatic reduction of the protein. These patients are considered affected by MEN 4 and present clinical features resembling MEN 1

Table 2 Relationship between CDKN1B polymorphism, somatic RET mutations, and some clinico-pathological features of the MTC patients. Somatic RET mutations were analyzed in a subgroup of $n=50$ patients and were found in $13 / 50$ patients (26\%). Twelve cases $(24 \%)$ had the M918T, and a single patient (2\%) had the C634W mutation. The CDKN1BPOL group comprises the combination of T/G and $\mathrm{G} / \mathrm{G}$ alleles; the WT group refers to the T/T allele.

\begin{tabular}{|c|c|c|c|c|c|c|c|c|}
\hline \multirow[b]{2}{*}{ Variables } & \multirow[b]{2}{*}{$n$} & \multicolumn{3}{|c|}{ CDKN1B POL } & \multicolumn{3}{|c|}{ CDKN1B WT } & \multirow[b]{2}{*}{$P$ value } \\
\hline & & RET - & RET + & (\%) & RET - & RET + & $(\%)$ & \\
\hline Metastasis & & & & & & & & $0.018^{\star}$ \\
\hline Mo & 43 & 15 & 6 & (48.9) & 18 & 4 & $(51.1)$ & \\
\hline M1 & 7 & 2 & 0 & (28.5) & 2 & 3 & (71.5) & \\
\hline T stage & & & & & & & & $0.023^{\star}$ \\
\hline T1/T2 & 37 & 15 & 4 & $(51.0)$ & 16 & 2 & $(49.0)$ & \\
\hline T3/T4 & 13 & 2 & 2 & $(30.0)$ & 4 & 5 & (70.0) & \\
\hline Last CT & & & & & & & & $0.042^{*}$ \\
\hline$\leq 10$ & 23 & 11 & 0 & $(48.0)$ & 10 & 2 & $(52.0)$ & \\
\hline$>10-150$ & 16 & 5 & 4 & (56.2) & 7 & 0 & (43.8) & \\
\hline$>150$ & 11 & 1 & 2 & (27.0) & 3 & 5 & (73.0) & \\
\hline Total & 50 & 17 & 6 & & 20 & 7 & & \\
\hline
\end{tabular}

Last $C T$, last post-operative calcitonin levels; $R E T+, R E T$ mutation positive; $R E T-, R E T$ mutation negative. ${ }^{\star}$ Significant at 0.05 level. 
Table 3 Univariate and multivariate Cox's proportional hazard analysis in MTC patients. Cox regression analysis was performed on all available patients $(n=83)$ or on the subgroup of patients analyzed for $R E T$ somatic mutations $(n=50)$. The CDKN1B WT group refers to the $T / T$ allele; the $P O L$ group comprises the combination of $T / G$ and $G / G$ alleles.

\begin{tabular}{|c|c|c|c|c|c|c|c|c|}
\hline \multirow[b]{3}{*}{ Parameters } & \multicolumn{4}{|c|}{ All patients $(n=83)$} & \multicolumn{4}{|c|}{ Subgroup $(n=50)$} \\
\hline & \multicolumn{2}{|c|}{ Univariate } & \multicolumn{2}{|c|}{ Multivariate adj. HR } & \multicolumn{2}{|l|}{ Univariate } & \multicolumn{2}{|c|}{ Multivariate adj. HR } \\
\hline & $\mathrm{HR}(95 \% \mathrm{Cl})$ & $P$ & $\mathrm{HR}(95 \% \mathrm{Cl})$ & $P$ & $\mathrm{HR}(95 \% \mathrm{Cl})$ & $P$ & $\mathrm{HR}(95 \% \mathrm{Cl})$ & $P$ \\
\hline $\begin{array}{l}C D K N 1 B \\
\text { (WT versus } \mathrm{POL})\end{array}$ & $1.81(0.98-3.31)$ & $0.048^{*}$ & $1.96(1.03-3.73)$ & $0.04^{\star}$ & $2.02(0.89-4.59)$ & 0.067 & $2.42(1.04-5.60)$ & $0.038^{*}$ \\
\hline Gender ( $\mathrm{M}$ versus F) & $1.43(1.03-3.25)$ & 0.070 & & & $1.89(1.14-5.71)$ & 0.160 & & \\
\hline Age $(\leq 45$ vs $>45)$ & $1.11(0.62-1.98)$ & 0.730 & & & $1.28(0.59-2.75)$ & 0.528 & & \\
\hline $\begin{array}{l}\text { Tumour stage } \\
\text { (III/IV vs I/II) }\end{array}$ & $1.72(1.23-2.40)$ & $0.002^{\dagger}$ & $1.67(1.18-2.35)$ & $0.004^{\dagger}$ & $2.35(1.46-3.77)$ & $0.000^{\dagger}$ & & \\
\hline $\begin{array}{l}\text { RET mutation } \\
\quad(+ \text { ve versus }- \text { ve })\end{array}$ & & & & & $2.23(1.03-4.84)$ & $0.042^{*}$ & $2.68(1.21-5.92)$ & $0.015^{\star}$ \\
\hline
\end{tabular}

+ ve, positive; -ve, negative; adj. HR, adjusted HR; WT $=C D K N 1 B$ wild-type-bearing patients; $\mathrm{POL}=C D K N 1 B$ polymorphism-bearing patients. *Significant at 0.05 level; ${ }^{\dagger}$ Significant at 0.01 level.

syndrome $(3,4)$. More recently, CDKN1B germline mutations have been described in multiple endocrine tumors (7). CDKN1B also harbors numerous polymorphisms that in several tumors have been variably associated with disease progression and patients' outcome (11-16). Specifically, the V109G polymorphism has been shown to have a protective effect on the overall patients' survival in sporadic pancreatic cancer (16). Subsequent surveys on tumors of different origins have produced conflicting results, leaving unanswered the question as to whether the CDKN1B V109G polymorphism is associated with a better or worse prognosis (11-15). In this study, we investigated whether CDKN1B mutations or polymorphisms could be associated with MTC disease progression. The only DNA variation detected was a $\mathrm{T} / \mathrm{G}$ transversion at position 326 that corresponds to the valine to glycine substitution at codon 109 of the mature protein. A borderline difference in the frequency of the wild-type and polymorphic alleles was found between patients and controls. Patients were selected to exclude those presenting C-cell hyperplasia, those related to inherited MEN 2 syndromes or FMTCs, or those associated with paragangliomas in various localizations or any other tumor. The participants were enrolled during the last 10 years (1999-2009) on the basis of the initial diagnosis and surgery performed at least 2-4 years earlier to have a sufficient long time span to evaluate the incidence of recurrence or the extent of the survival. We provide evidence that MTC patients bearing the CDKN1B V109G polymorphic allele have more frequently last post-operative basal serum calcitonin levels in the normal range than those bearing the wild-type allele (Fig. 2). Interestingly, the POL patients have a significantly lower rate of clinical recurrence, distant metastases, and hence a better outcome, suggesting that the V109G polymorphism may modulate MTC progression and be protective against recurrences (Table 1). Consistent with this, patients bearing the polymorphism, although presenting moderately elevated calcitonin levels, have a more indolent disease course than those with the wild-type allele and similar calcitonin levels. Somatic RET mutations appear to worsen disease progression in wild-type allele-bearing patients, as documented by a shorter DFS, stage of the tumor, and presence of distant metastases. In patients bearing the polymorphic allele, instead, RET mutations do not have the same impact confirming that the polymorphic allele exerts a protective effect against a more aggressive disease. In line with this, a significant interaction of the CDKN1B V109G polymorphism with somatic RET mutations was observed in a multivariate analysis. Laboratory and imaging data as well as clinical evidences supported this hypothesis. This is the first study reporting that the CDKN1B V109G polymorphism is associated with a lower risk to develop MTC recurrences. By multivariate analysis, a significant association was found with the tumor stage, whereas no significant modifying effects were observed by any of the other variables assessed.

Inspection of the three-dimensional structure of the protein provides insight into the molecular basis of the behavior of the p27Kip1 variant. The structure of the Nand C-terminal regions of the protein has been resolved, and the interacting protein complexes are identified $(29$, 30). The intermediate region, comprising amino acid residues 97-151, appears to be involved in the binding with p38/JAB1, required for its nuclear export and subsequent degradation (31). In fact, replacement of the aspartic acid at position 108 with a glycine residue affects the formation of the complex. It has been postulated that any amino acid change around this position, as the V109G polymorphism, could impair this interaction, reduce p27kip1 cytosolic translocation, increasing its nuclear stability. These events might lead to a reduced cell growth and hence explain the protective role found in MTC $(31,32)$. No experimental data have been provided so far, and more studies are needed to 
confirm this hypothesis. The CDKN1B polymorphism may also be in linkage disequilibrium with other functional polymorphisms that affect either the expression or the activity of enzymes involved in tumorigenesis.

In conclusion, the CDKN1B V109G polymorphism might influence the clinical course of patients presenting sporadic MTC. The assessment of the CDKN1B genotype might be a new tool for MTC prognosis along with other known markers, such as the last postoperative serum calcitonin and RET mutations' detection. Further studies will allow a better understanding of the molecular basis of the proposed protective effect of the CDKN1B polymorphism in sporadic MTC.

\section{Declaration of interest}

The authors declare that there is no conflict of interest that could be perceived as prejudicing the impartiality of the research reported.

\section{Funding}

This work was partially supported by AIRC (Associazione Italiana per la Ricerca sul Cancro) and AIL (Associazione Italiana per la lotta alle leucemie e linfomi sezione di Benevento) to $\mathrm{V}$ Colantuoni and PRIN 2008 (Programmi di ricerca di Rilevante Interesse Nazionale) to D Pasquali.

\section{References}

1 Polyak K, Lee MH, Erdjument-Bromage H, Koff A, Roberts JM, Tempst P \& Massague J. Cloning of p27Kip1 a cyclin dependent kinase inhibitor and a potential mediator of extracellular antimitogenic signals. Cell 199478 59-66. (doi:10.1016/00928674(94)90572-X)

2 Toyoshima H \& Hunter T. p27Kip1, a novel inhibitor of G1 cyclinCdk protein kinase activity, is related to p21. Cell $1994 \mathbf{7 8} 67-74$. (doi:10.1016/0092-8674(94)90573-8)

3 Pellegata NS, Quintanilla-Martinez L, Siggelkow H, Samson E, Bink K, Höfler H, Fend F, Graw J \& Atkinson MJ. Germline mutations in p27Kip1 cause a multiple endocrine neoplasia syndrome in rats and humans. PNAS 2006103 15558-15563. (doi:10.1073/pnas.0603877103)

4 Agarwal SK, Mateo CM \& Marx SJ. Rare germline mutations in cyclin-dependent kinase inhibitor genes in multiple endocrine neoplasia type 1 and related states. Journal of Clinical Endocrinology and Metabolism 200994 1826-1834. (doi:10.1210/jc.20082083)

5 Alevizaki M \& Stratakis CA. Multiple endocrine neoplasias: advances and challenges for the future. Journal of Internal Medicine 2009266 1-4. (doi:10.1111/j.1365-2796.2009.02108.x)

6 Ozawa A, Agarwal SK, Mateo CM, Burns AL, Rice TS, Kennedy PA, Quigley CM, Simonds WF, Weinstein LS, Chandrasekharappa SC, Collins FS, Spiegel AM \& Marx SJ. The parathyroid/pituitary variant of multiple endocrine neoplasia type 1 usually has causes other than p27Kip1 mutations. Journal of Clinical Endocrinology and Metabolism 200792 1948-1951. (doi:10.1210/jc.2006-2563)

7 Molatore S, Marinoni I, Lee M, Pulz E, Ambrosio MR, degli Uberti EC, Zatelli MC \& Pellegata NS. A novel germline CDKN1B mutation causing multiple endocrine tumors: clinical, genetic and functional characterization. Human Mutation 201031 1825-1835. (doi:10.1002/humu.21354)

8 Igreja S, Chahal HS, Akker SA, Gueorguiev M, Popovic V, Damjanovic S, Burman P, Wass JA, Quinton R, Grossman AB \& Korbonits M. Assessment of p27 (cyclin-dependent kinase inhibitor 1B) and AIP (aryl hydrocarbon receptor-interacting protein) genes in MEN 1 syndrome patients without any detectable MEN 1 gene mutations. Clinical Endocrinology 200870 259-264. (doi:10.1111/j.1365-2265.2008.03379.x)

9 Georgitsi M, Raitila A, Karhu A, van der Luijt RB, Aalfs CM, Sane T, Vierimaa O, Mäkinen MJ, Tuppurainen K, Paschke R, Gimm O, Koch CA, Gündogdu S, Lucassen A, Tischkowitz M, Izatt L, Aylwin S, Bano G, Hodgson S, De Menis E, Launonen V, Vahteristo P \& Aaltonen LA. Germline CDKN1B/p27Kip1 mutation in multiple endocrine neoplasia. Journal of Clinical Endocrinology and Metabolism 200792 3321-3325. (doi:10.1210/jc.2006-2843)

10 Cavé H, Martin E, Devaux I \& Grandchamp B. Identification of a polymorphism in the coding region of the p27Kip1 gene. Annales de Genetique $19953 \mathbf{8} 108$.

11 Kibel AS, Suarez BK, Belani J, Oh J, Webster R, Brophy-Ebbers M, Guo C, Catalona WJ, Picus J \& Goodfellow PJ. CDKN1A and $C D K N 1 B$ polymorphisms and risk of advanced prostate carcinoma. Cancer Research 200363 2033-2036.

12 Chang BL, Zheng SL, Isaacs SD, Wiley KE, Turner A, Li G, Walsh PC, Meyers DA, Isaacs WB \& Xu J. A polymorphism in the CDKN1B gene is associated with increased risk of hereditary prostate cancer. Cancer Research 200464 1997-1999. (doi:10. 1158/0008-5472.CAN-03-2340)

13 Ma H, Jin G, Hu Z, Zhai X, Chen W, Wang S, Wang X, Qin J, Gao J, Liu J, Wang X, Wei Q \& Shen H. Variant genotypes of CDKN1A and CDKN1B are associated with an increased risk of breast cancer in Chinese women. International Journal of Cancer $20061192173-$ 2178. (doi:10.1002/ijc.22094)

14 Figueiredo JC, Knight JA, Cho S, Savas S, Onay UV, Briollais L, Goodwin PJ, McLaughlin JR, Andrulis IL \& Ozcelik H. Polymorphisms cMyc-N11S and p27-V109G and breast cancer risk and prognosis. BMC Cancer 20077 99-106. (doi:10.1186/14712407-7-99)

15 Li G, Sturgis EM, Wang LE, Chamberlain RM, Spitz MR, El-Naggar AK, Hong WK \& Wei Q. Association between the V109G polymorphism of the $\mathrm{p} 27$ gene and the risk and progression of oral squamous cell carcinoma. Clinical Cancer Research 200410 3996-4002. (doi:10.1158/1078-0432.CCR-04-0089)

16 Chen J, Li D, Killary AM, Sen S, Amos CI, Evans DB, Abbruzzese JL \& Frazier ML. Polymorphisms of p16, p27, p73, and MDM2 modulate response and survival of pancreatic cancer patients treated with preoperative chemoradiation. Annals of Surgical Oncology 2009 16 431-439. (doi:10.1245/s10434-008-0220-8)

17 Jiménez C, Hu MIN \& Gagel RF. In thyroid tumors: management of medullary thyroid carcinoma. Endocrinology and Metabolism Clinics of North America 200837 481-496. (doi:10.1016/j.ecl. 2008.03.001)

18 Schlumberger M, Carlomagno F, Baudin E, Bidart JM \& Santoro M. New therapeutic approaches to treat medullary thyroid carcinoma. Nature Clinical Practice. Endocrinology and Metabolism 2008 4 22-32. (doi:10.1038/ncpendmet0717)

19 Cote GJ \& Gagel RF. Lessons learned from the management of a rare genetic cancer. New England Journal of Medicine 2003349 1566-1568. (doi:10.1056/NEJMe038148)

20 Zbuk KM \& Eng C. Cancer phenomics: RET and PTEN as illustrative models. Nature Reviews. Cancer $2007 \quad 7 \quad 35-45$. (doi:10.1038/nrc2037)

21 Elisei R, Romei C, Cosci B, Agate L, Bottici V, Molinaro E, Sculli M, Miccoli P, Basolo F, Grasso L, Pacini F \& Pinchera A. RET genetic screening in patients with medullary thyroid cancer and their relatives: experience with 807 individuals at one center. Journal of Clinical Endocrinology and Metabolism 200792 4725-4729. (doi:10.1210/jc.2007-1005)

22 Cerrato A, De Falco V \& Santoro M. Molecular genetics of medullary thyroid carcinoma: the quest for novel therapeutic targets. Journal of Molecular Endocrinology 200943 143-155. (doi:10.1677/JME-09-0024)

23 Mulligan LM, Kwok JB, Healey CS, Elsdon MJ, Eng C, Gardner E, Love DR, Mole SE, More JK, Papi L, Ponder MA, Telenius H, Tunnacliffe A \& Ponder BAJ. Germ-line mutations of the RET proto-oncogene in multiple endocrine neoplasia type $2 \mathrm{~A}$. Nature 1993363 458-460. (doi:10.1038/363458a0) 
24 Donis-Keller H, Dou S, Chi D, Carlson KM, Toshima K, Lairmore TC, Howe JR, Moley JF, Goodfellow P \& Wells SA Jr. Mutations in the RET proto-oncogene are associated with MEN 2A and FMTC. Human Molecular Genetics 19932 851-856. (doi:10. $1093 / \mathrm{hmg} / 2.7 .851$ )

25 Kloos RT, Eng C, Evans DB, Francis GL, Gagel RF, Gharib H, Moley JF, Pacini F, Ringel MD, Schlumberger M \& Wells SA Jr. Medullary thyroid cancer: management guidelines of the American Thyroid Association the American Thyroid Association Guidelines Task Force*. Thyroid 200919 565-612. (doi:10.1089/thy.2008.0403)

26 Faggiano A, Milone F, Ramundo V, Chiofalo MG, Ventre I, Giannattasio R, Severino R, Lombardi G, Colao A \& Pezzullo L. A decrease of calcitonin serum concentrations less than 50 percent 30 minutes after thyroid surgery suggests incomplete C-cell tumor tissue removal. Journal of Clinical Endocrinology and Metabolism 2010 95 32-36. (doi:10.1210/jc.2010-0045)

27 Elisei R, Cosci B, Romei C, Bottici V, Renzini G, Molinaro E, Agate L, Vivaldi A, Faviana P, Basolo F, Miccoli P, Berti P, Pacini F \& Pinchera A. Prognostic significance of somatic RET oncogene mutations in sporadic medullary thyroid cancer: a 10-year followup study. Journal of Clinical Endocrinology and Metabolism 200893 682-687. (doi:10.1210/jc.2007-1714)

28 Scurini C, Quadro L, Fattoruso O, Verga U, Libroia A, Lupoli G, Cascone E, Marzano L, Paracchi S, Busnardo B, Girelli ME, Bellastella A \& Colantuoni V. Germ-line and somatic mutations of the RET proto-oncogene in apparently sporadic medullary thyroid carcinomas. Molecular and Cellular Endocrinology 1998 137 51-57. (doi:10.1016/S0303-7207(97)00234-7)

29 Russo AA, Jeffrey PD, Patten AK, Massagué J \& Pavletich NP. Crystal structure of the p27Kip1 cyclin-dependent-kinase inhibitor bound to the cyclin A-Cdk2 complex. Nature 1996 382 325-331. (doi:10.1038/382325a0)

30 Hao B, Zheng N, Schulman BA, Wu G, Miller JJ, Pagano M \& Pavletich NP. Structural basis of the Cks1-dependent recognition of p27(Kip1) by the SCF(Skp2) ubiquitin ligase. Molecular Cell 200520 9-19. (doi:10.1016/j.molcel.2005.09.003)

31 Tomoda K, Kubota Y, Arata Y, Mori S, Maeda M, Tanaka T, Yoshida M, Yoneda-Kato N \& Kato JY. The cytoplasmic shuttling and subsequent degradation of p27Kip1 mediated by Jab1/CSN 5 and the COP9 signalosome complex. Journal of Biological Chemistry 2002277 2302-2310. (doi:10.1074/jbc.M104431200)

32 Chu IM, Hengst L \& Slingerland JM. The Cdk inhibitor p27 in human cancer: prognostic potential and relevance to anticancer therapy. Nature Reviews. Cancer 2008 8 253-267. (doi:10.1038/ nrc2347)

Received 1 December 2010

Accepted 21 December 2010 